Journal of Animal and Veterinary Advances 10 (5): 601-605, 2011

ISSN: $1680-5593$

(C) Medwell Journals, 2011

\title{
Ethanolic Extract of Eucheuma cottonii Promotes in vivo Hair Growth and Wound Healing
}

\author{
${ }^{1}$ Samaneh Ghasemi Fard, ${ }^{2}$ Fatemeh Tash Shamsabadi, ${ }^{3}$ Mozhdeh Emadi, ${ }^{4}$ Goh Yong Meng, \\ ${ }^{1}$ Kharidah Muhammad and ${ }^{1}$ Suhaila Mohamed \\ ${ }^{1}$ Faculty of Food Science and Technology, ${ }^{2}$ Institute of Bioscience, ${ }^{3}$ Department of Animal Science, \\ Faculty of Agriculture, ${ }^{4} \mathrm{Faculty}$ of Veterinary Medicine, Universiti Putra Malaysia, \\ UPM 43400 Serdang, Selangor, Malaysia
}

\begin{abstract}
Hair is considered to be a major component of an individual's general appearance. It is also psychosocial important and patients both men and women with hair loss (alopecia) often deeply suffer. Demand for medications that alter hair growth and appearance has led to a multibillion-dollar industry and thus far few natural effective products are available. For the purpose of ascertaining natural products which possess hair growing activity we looked over onto ethanolic and aqueous extracts of $E$. cottonii. Hair follicle epithelial stem cells and their contribution to skin healing have attracted particular attention. Oral treatments commenced soon after shaving the dorsal interscapular area of healthy male Sprague-Dawley rats. Microscopic observations of skin were performed. This study showed ethanolic extract of $E$. cottonii enhanced hair growth by higher proliferative activity. Ethanolic extract of this seaweed increased the rate of wound contraction and epithelization when compared to positive and negative control groups. The ethanolic extract of $E$. cottonii was approximately $20 \%$ more effective than aqueous extraction. The extraction also possesses several antioxidant compounds which may be responsible for the accelerated hair growth and wound healing. We demonstrated for the first time in the present study that this seaweed extracts revealed faster healing and hair growth even when compared with positive control group.
\end{abstract}

Key words: Seaweed (Eucheuma cottonii), hair growth, wound healing, ethanolic extract, antioxidant, ascertaining

\section{INTRODUCTION}

Many plants have been traditionally utilized for curing male pattern baldness. However, in most instances the efficacy was not determined (Takahashi et al., 1998). $E$. cottonii is an edible species of Malaysian seaweeds obtained from Sabah waters (Semporna) which have been exposed as a novel sources for varieties of compounds such as dietary fibers, vitamin $\mathrm{C}, \alpha$-tocopherol, minerals, fatty acid and protein (Matanjun et al., 2008).

Seaweeds also are considered to be rich source of antioxidants. The potential antioxidant compounds were identified as some pigments (fucoxanthin, astaxanthin, carotenoid) and polyphenols (phenolic acid, flavonoid, tannins) (Chew et al., 2008; Chandini et al., 2008). The biological activity of antioxidants has been documented as anticoagulant, anti-tumour, anti-inflammatory and antidiabetics (Hyun et al., 2006). Takahashi et al. (1998) also showed proanthocyanidins, a species of condensed tannin, extracted from grape seeds is an active element in treatment of androgenetic alopecia. The objective of this study was to evaluate the potential wound healing and hair growing properties of ethanolic and aqueous extracts of Eucheuma cottonit.

\section{MATERIALS AND METHODS}

$E$. cottonii extract preparation: $E$. cottonii was collected from the coastal areas of Semporna (Sabah, Malaysia). In the laboratory, the fresh seaweeds were cleaned, washed with distilled water and their holdfasts and epiphytes were removed. The seaweed was then dried at $40^{\circ} \mathrm{C}$ in dark room for 3 days and then was grounded to fine powder using a Warring miller to be able to pass through a $0.5 \mathrm{~mm}$ screen. Subsequently, it was stored in air-tight containers covered by aluminum foil at $-20^{\circ} \mathrm{C}$. Plant extract was prepared from the fine powder within a month. Ethanol and water extracts were prepared based on method of Ponce et al. (2003) with modification. The ethanolic extract was prepared from milled seaweed $(200 \mathrm{~g})$ using $1000 \mathrm{~mL}$

Corresponding Author: Suhaila Mohamed, Faculty of Food Science and Technology, Universiti Putra Malaysia, UPM 43400 Serdang, Selangor, Malaysia 
of $80 \%(\mathrm{v} / \mathrm{v})$ ethanol under mechanical stirring at room temperature for $24 \mathrm{~h}$ and filtered. The residue was then dissolved in $3000 \mathrm{~mL}$ distilled water, stirred at room temperature $\left(25 \pm 2^{\circ} \mathrm{C}\right)$ for $8 \mathrm{~h}$ and then filtered. Subsequently, the ethanolic and aqueous extracts were concentrated under negative pressure at 40 and $70^{\circ} \mathrm{C}$ for $1 \mathrm{~h}$, respectively. Both extracts were then oven dried at $40^{\circ} \mathrm{C}$ overnight which produced powdered extracts. The powdered extracts were then stored in air-tight containers at $-20^{\circ} \mathrm{C}$ until application.

Animal and design: Forty eight 10-12 week old healthy male Sprague-Dawley rats weighing 300-350 g were used for wound healing and hair growth experiment. They were allotted randomly into four groups with twelve animals. The rats were acclimatized for 1 week prior to the study. Animals were housed in individual cages and kept in a ventilated room with temperature regulated at $23 \pm 2^{\circ} \mathrm{C}$, with a $12 \mathrm{~h}$ light and $12 \mathrm{~h}$ dark cycle. They were fed with commercial rat pellets and water was supplied ad libitum. Experimental procedures and animal care had been approved by the Institutional Animal Care and Use Committee (IACUC), Faculty of Veterinary Medicine, UniversitiPutraMalaysia(UPM/FPV/PS/3.2.1.551/AUP-R17).

Wound formation and treatment: Treatment groups were comprised of one positive and one negative control groups and 2 groups of animals treated with powdered extraction dissolved in distilled water to the desired concentrations. Four treatment groups in this study were Group $\mathrm{A}$; animals treated by $\mathrm{PO}$ administration of ethanolic extract of seaweed, Group B; animals in this group received oral treatment of aqueous extract of seaweed Group C; positive control group that was treated by $\mathrm{PO}$ administration of honey and Group $\mathrm{D}$; negative Control group which treated orally with distilled water.

The rats were anaesthetized with ketamine HCL (120 $\mathrm{mg} \mathrm{kg}^{-1}$ body weight) prior to wound induction. Wound site at dorsal interscapular area was prepared and shaved preceding to surgery. A full thickness circular wound with an area of $300 \mathrm{~mm}^{2}$ was incised. Immediately after wound induction, it was washed with normal saline and covered by a film dressing. Oral treatments commenced soon after wound creation. Rats were fed $100 \mathrm{mg} \mathrm{kg}^{-1}$, SID with extracts of $E$. cottonii using gastric tube.

Sampling, wound healing and hair growth evaluation: Wounds were traced on $1 \mathrm{~mm}^{2}$ graph paper on the day of induction and planimetrically, every 3 days for 2 weeks. Wound contraction was calculated as percent reduction

in wound area (Nayak et al., 2005). Half rats in each group were sacrificed on day 15 post operation with ketamine overdose and the rest maintained to be check for period of epithelization. Collected samples were rinsed with $0.2 \mathrm{M}$ phosphate buffered saline (PBS, $\mathrm{pH} 7.4$ ) and fixed in $4 \%$ paraformaldehyde. They were then embedded in paraplast wax after further processing and sectioned into $5 \mu \mathrm{m}$ thick ribbons. The tissue samples were then mounted stained with hematoxylin and eosin $(\mathrm{H}$ and $\mathrm{E})$ and observed under light microscope. Samples were evaluated for extent of wound contraction and hair growth.

Statistical analysis: All results were revealed as means \pm Standard Deviation (SD) and were analyzed by one-way Analysis of Variance (ANOVA) followed by Duncan multiple range tests. All procedures were performed at 95\% confidence level using the Minitab 14.

\section{RESULTS AND DISCUSSION}

Wound contraction: Wound contraction is the factor indicating rate of reduction of unhealed area during the period of treatment. Wound contraction occurs as the myofibroblasts contract. Increased wound contraction in treated rats might be a result of enhanced activity of fibroblasts in the treated rats. Wound contraction is mediated by specialized myofibroblasts found in the granulated tissue (Moulin et al., 2000). Table 1 shows the rate of wound contraction expressed in terms of the percentage of healed wound area. On 15 th day there was a significantly difference in percentage of wound closure $(p<0.05)$ between the control and the test groups. It is manifested that group. A rats showed 100\% healing, whereas group B rats showed $83.44 \%$ and group C showed $93.76 \%$ when compared to the controls $(52.66 \%)$. The least percentage of wound healing was seen in negative control group which had not received any treatment.

Period of epithelization: Some of the phases of healing such as wound contraction and epithelialization run concurrently and independently (Kaushal et al., 2007). Epithelization is the process in which epithelial cells around the margin of the wound or in residual skin appendages (hair follicles and sebaceous glands) begin to

Table 1: The wound healing (\%) of different groups of rats fed with $E$. cottonii extracts over a period of 15 days

\begin{tabular}{lccccc}
\hline Groups & Day 3 & Day 6 & Day 9 & Day 12 & Day 15 \\
\hline A & $8.67 \pm 0.42^{\mathrm{a}}$ & $37.92 \pm 8.61^{\mathrm{a}}$ & $79.96 \pm 1.57^{\mathrm{a}}$ & $92.35 \pm 4.000^{\mathrm{a}}$ & $100.00 \pm 0.00^{\mathrm{a}}$ \\
$\mathrm{B}$ & $3.36 \pm 0.78^{\mathrm{b}}$ & $19.82 \pm 5.04^{\mathrm{a}}$ & $50.09 \pm 6.83^{\mathrm{b}}$ & $70.16 \pm 4.970^{\mathrm{a}}$ & $83.44 \pm 2.01^{\mathrm{b}}$ \\
$\mathrm{C}$ & $8.23 \pm 2.27^{\mathrm{a}}$ & $34.08 \pm 8.50^{\mathrm{b}}$ & $58.34 \pm 6.53^{\mathrm{b}}$ & $72.77 \pm 9.790^{\mathrm{a}}$ & $93.76 \pm 3.25^{\mathrm{b}}$ \\
$\mathrm{D}$ & $0.63 \pm 0.40^{\mathrm{b}}$ & $23.48 \pm 8.81^{\mathrm{a}}$ & $35.40 \pm 7.26^{\mathrm{c}}$ & $40.30 \pm 13.00^{\mathrm{b}}$ & $52.66 \pm 8.56^{\mathrm{c}}$ \\
Value are mean $\pm \mathrm{SE}$ of 6 animals in each group; means with different \\
Superscripts within a column were significantly different at p<0.05; (A, \\
ethanolic extract group; B, aqueous extract group; C, treated group with \\
honey; D, no treated group)
\end{tabular}


migrate into the wound by the process known as epiboly (Stenn and Cotsarelis, 2005). Re-epithelization had taken 9 days in ethanolic extract treated groups in contrast to 20 days in the control group. On the 15 day post treatment, all groups completely covered with fibrin except for the negative control group. It can be concluded that effect of $E$. cottonii extract oral treatment on skin lesions could accelerate the reepithelization and remodelling phases (Table 2).

Percentage of hair growth: In this research, hair growth on shaved skin near the wound site was monitored. As reported by Geoffrey et al. (2008), dermal structures such as hair follicles, sweat glands and sebaceous glands that are lost during injuries would not be regenerated. Group which was treated with ethanolic extract of $E$. cottonii (Group A) showed the best result for hair growth. In this group $95-100 \%$ of the shaven area showed hair re-growth. Growth of hair in rats treated with aqueous extract of the seaweed (Group B) was less than that of the rats treated with honey (the percentages of covering were $45-50 \%$ and

Table 2: Period of epithelialization (day) of rats fed with $E$. cottonii extracts

\begin{tabular}{lcccc}
\hline Groups & A & B & C & D \\
\hline Period of & $9.0 \pm 0.4^{\mathrm{a}}$ & $14.8 \pm 0.7^{b}$ & $12.1 \pm 0.8^{b}$ & $20.0 \pm 0.8^{c}$
\end{tabular}
epithelialization

Values are mean \pm SD $(p<0.05$ ); (A: Ethanolic extract group; B: Aqueous extract group; C: Treated group with honey; D: No treated group)
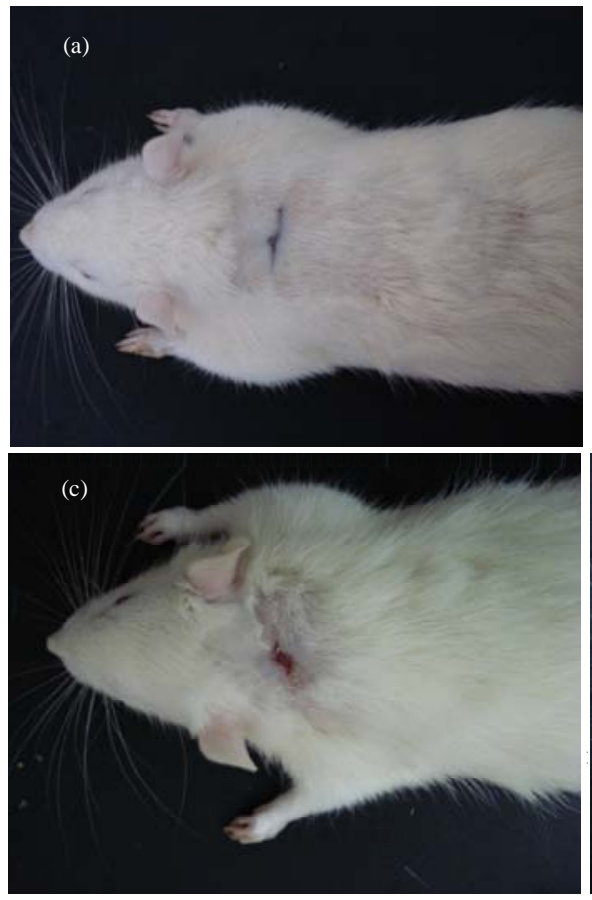

$75-80 \%$, respectively). Control group showed the least hair growth (25-30\%). Figure 1 shows the faster wound healing and hair growth in ethanolic extract of the seaweed. There was a direct relation between hair follicle growth and dermis repair approach. Hair follicle dermal cells produce wound healing fibroblasts and their participation in wound healing reduces the probability of scarring. Fibroblasts are prominent in granulation tissue and important for wound contraction (Naik-Mathuria et al., 2008). Hair follicle epithelial stem cells and its contribution to wound healing have attracted particular attention (Taylor et al., 2000). Jahoda and Reynolds (2000) have shown that labeled dermal sheath cells introduced into skin wounds make up parts of healed dermis several weeks later and could also create a dermis from dermal sheath cells in rodents which supports growth of a normal-looking epidermis. Taylor et al. (2000) also suggested that hair follicle dermal sheath cells act as specialized progenitor fibroblast populations that are activated in response to wound induction. In another major study, Naik-Mathuria et al. (2008) found that these myofibroblasts are also prominent in granulation tissue and important in wound contraction procedure.

Hair follicle counts: Table 3 shows the average number of hair follicles, area size of hair bulb and length of hair
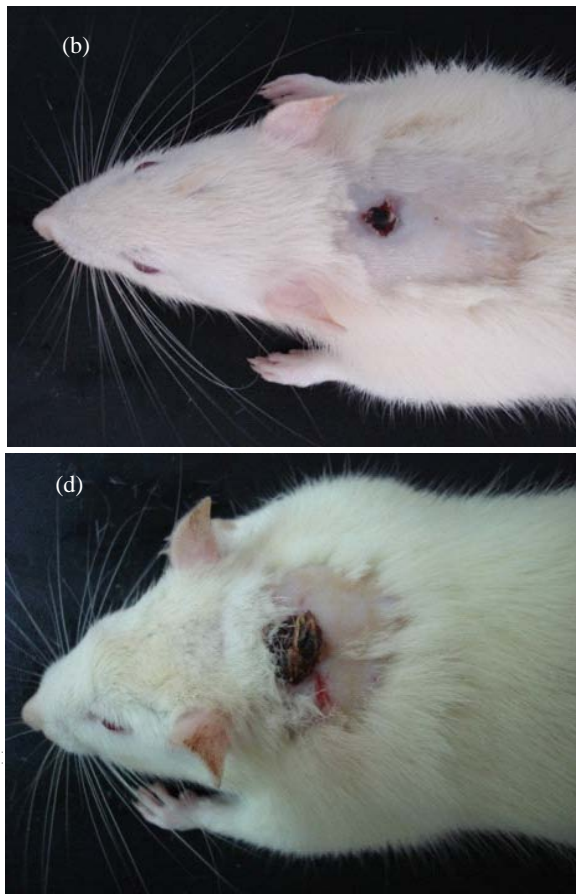

Fig. 1: Photograph showing the hair growth in the different groups at the 15 day post treatment. Group A treated with ethanolic extract of $E$. cottonii, Group B treated with aqueous extract of the seaweed in Group C honey was used and Group D received distilled water. Shaved skin site covered with hair completely only in Group A 
Table 3: Number of hair follicle, area size of hair bulb and length of hair follicle around the wound in rats treated with various extractions of $E$. cottonii at day

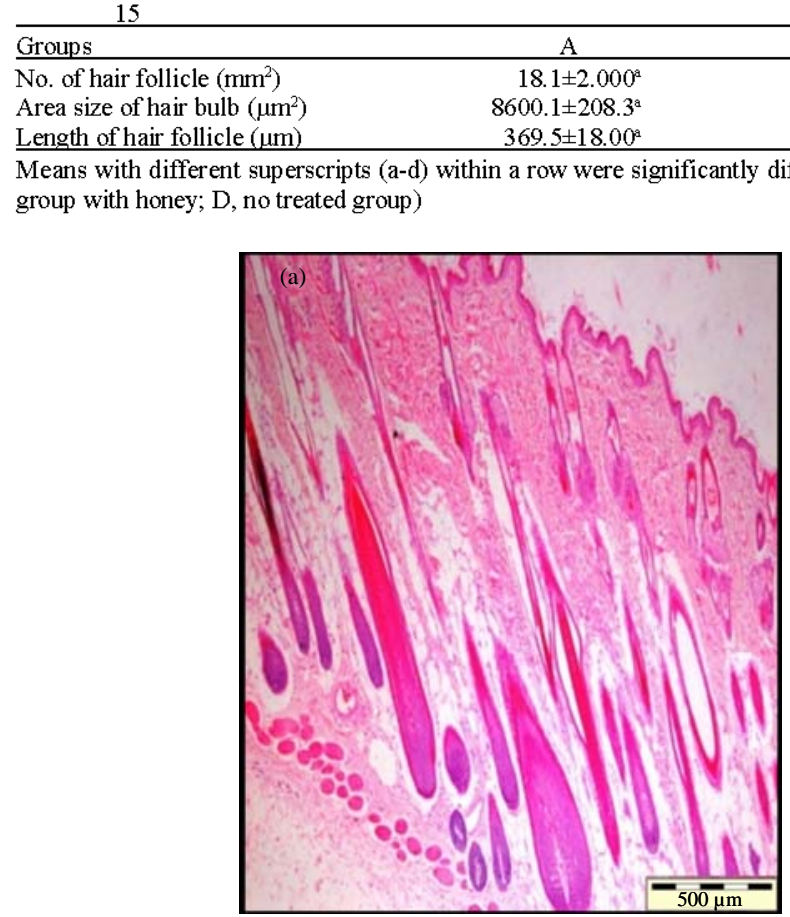
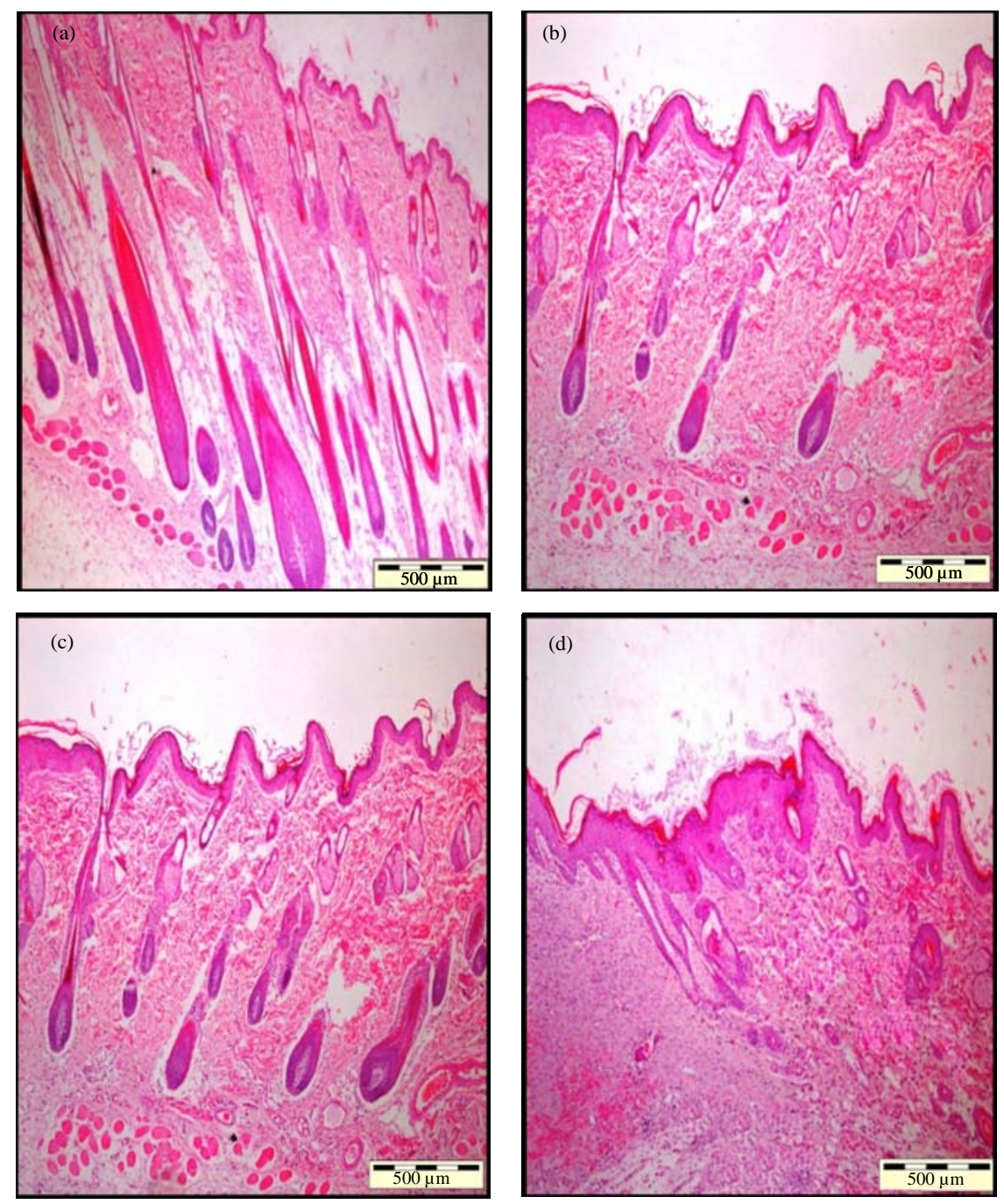

Fig. 2: Micrographs of hair follicle after 15 days oral treatment in different treated groups $(\mathrm{H}$ and $\mathrm{E}$ stain; $\times 40)$. Group A treated with ethanolic extract of $E$. cottonii, Group B treated with aqueous extract of the seaweed in Group C honey was used and Group D received distilled water

follicle around the wound site in animals treated with various extractions of $E$. cottonii at day 15. Ethanolic extract of seaweed (Group A) showed a significant increase $(\mathrm{p}<0.05)$ in hair follicle number at 15 day post treatment. All major structures of the hair follicle were in mature phase with biggest bulb and maximum length. In aqueous extract group (Group B) there were early signs of newly formed hair follicles with an averages number of hair follicles. Hair follicle had a smaller bulb and a narrower dermal papillaries. Hair follicle length was shorter in comparison with the ethanolic extract group. In the positive control group there was modest numbers of newly formed hair follicles whereas negative control group revealed the least population of follicle (Fig. 2). The 
results manifested earlier show the potentials of seaweed ethanolic extracts in boosting hair growth. It contains flavonoids which are antioxidants and undetermined substances which might cause proliferation of fibroblasts. Takahashi et al. (1998) described the potent positive influence of flavonoids on hair growth. They purified proanthocyanidins linked by catechin and epicatechin which possessed higher proliferation and hair re-growth activities.

\section{CONCLUSION}

Oral application of $E$. cottonii extracts could enhance cutaneous healing however it showed a faster trend in ethanolic extract which manifested a complete healing in 15 days. Also this group showed a faster hair growth rate during the time. There is a direct association between hair follicle growth and rate of dermis repair. It is shown that skin containing large actively growing follicles, heals more rapidly than skins with not well growing well follicles. Literature scan showed that phenotype of dermal sheath cells is closely relevant to dermal wound healing. Although, the controversies regarding nature and origin of wound healing fibroblasts, it is widely believed that specialized wound healing cells (myofibroblasts) are prominent in granulation tissue formation and wound contraction (Naik-Mathuria et al., 2008).

This study reported effectiveness of $E$. cottonii extracts in management of wound healing, hair growth and androgen-induced alopecia in the shortest possible period of time. It gives the impression that $E$. cottonii extracts (especially ethanolic form) could be used as a proper treatment approach in healing procedures and hair re-growth instances successfully and effectively however, further studies with purified components are required to appreciate the complete mechanism of wound healing and hair growing activity of ethanolic extract of $E$. cottonii.

\section{ACKNOWLEDGEMENTS}

Researchers would like to thank Mr. Kufli Che Noor for his supports in the animal study. This study was supported by the Ministry of Higher Education Fundamental Research Grant Scheme (project no: 91030).

\section{REFERENCES}

Chandini, S.K., P. Ganesan and N. Bhaskar, 2008. In vitro antioxidant activities of three selected brown seaweeds of India. Food Chem., 107: 707-713.
Chew, Y.L., Y.Y. Lim, M. Omar and K.S. Khoo, 2008. Antioxidant activity of three edible seaweeds from two areas in South East Asia. LWT, 41: 1067-1072.

Geoffrey, C.G., W. Sabine, B. Yann and T.L. Michael, 2008. Review article wound repair and regeneration. Nature, 453: 314-321.

Hyun, J.A.H., S.K. Hyun, H.R. Kim and J.S. Choi, 2006. Angiotensin-converting enzyme I inhibitory activity of phlorotannins from Ecklonia stolonifera. Fish. Sci., 72: 1292-1299.

Jahoda, C.A.B. and A.J. Reynolds, 2000. Hair follicle dermal sheath cells: Unsung participants in wound healing. The Lancet, 358: 1445-1448.

Kaushal, M., N.G. Kutty and C. Mallikarjuna Rao, 2007. Wound healing activity of NOE-aspirin: A pre-clinical study. Nitric Oxide, 16: 150-156.

Matanjun, P., S. Mohamed, N.M. Mustapha, K. Muhammad and C.H. Ming, 2008. Antioxidant activities and phenolics content of eight species of seaweeds from north Borneo. J. Applied Phycol., 20: 367-373.

Moulin, V., F.A. Auger, D. Garel and L. Germain, 2000. Role of wound healing myofibroblasts on re-epithelization of human skin. Burns, 26: 3-12.

Naik-Mathuria, B., D. Pilling, J.R. Crawford, A.N. Gay and C.W. Smith, 2008. Serum amyloid P inhibits dermal wound healing. Wound Repair Regen, 16: 266-273.

Nayak, B.S., B. Vinutha, B. Geetha and B. Sudha, 2005. Experimental evaluation of Pentas lanceolata flowers for wound healing activity in rats. Fitoterapia, 76: 671-675.

Ponce, N.M.A., C.A. Pujol, E.B. Damonte, M.L. Flores and C.A. Stortz, 2003. Fucoidans from the brown seaweed Adenocystis utricularis: extraction methods, antiviral activity and structural studies. Carbohydr. Res., 338: 153-165.

Stenn, K.S. and G. Cotsarelis, 2005. Bioengineering the hair follicle: Fringe benefits of stem cell technology. Curr. Opin. Biotechnol., 16: 493-497.

Takahashi, T., T. Kamiya and Y. Yokoo, 1998. Proanthocyanidins from grape seeds promote proliferation of mouse hair follicle cells in vitro and convert hair cycle in vivo. Acta Dermato Venereologica, 78: 428-432.

Taylor, G., M.S. Lehrer, P.J. Jensen, T.T. Sun and R.M. Lavker, 2000. Involvement of follicular stem cells in forming not only the follicle but also the epidermis. Cell, 102: 451-461. 